\title{
Experimental Study on Family Formation and Moral Values of Students
}

\author{
Marfuga Absatovna Absatova ${ }^{1}$, Sabira Nishanbaeva ${ }^{1}$, Toleuzhan Baibolovna Nurpeisova ${ }^{2}$ \\ and Kalipa Tursunovna Atemova ${ }^{3}$
}

${ }^{1}$ Kazakh National Pedagogical University Abay, Abai Kazakh National Pedagogical University, 050010, Almaty, Dostyk Avenue, 13, Kazakhstan

${ }^{2}$ Kazakh Automobile -Road Goncharov Academy, 050061, Almaty, ul. Tashkent 415B, Kazakhstan

${ }^{3}$ International Kazakh-Turkish University Khoja Ahmed Yasawi, 161200, c.Turkestan, street B.Sattarkhanov, 29., Kazakhstan

\begin{abstract}
The relevance of the research topic is due to the diversity and complexity of the tasks of human education in the 21st century. The modernization processes taking place in the modern Kazakhstani society created a deep crisis of many aspects of social life, including negatively affecting the value orientations of the younger generation, led to the devaluation of family values, alienation of youth from institutions of upbringing. This significant transformation partly led to a change in the orientations and priorities in the educational process of students.

Analysis of the activity of higher education institutions in the education of family and moral values among students in the process of teaching and educational work made it possible to identify contradictions between:

- the acute need of modern society for the upbringing of family and moral values among students and the underestimation of the significance of the process of family education in general;

- the existing traditionally developed approach to determining the content of forms and methods of instruction and the objective needs of a qualitatively new attitude to the education of family and moral values among students in the process of education and educational work.

This study allowed us to draw the following conclusions. The essence of the concept of "value" was substantiated, the content of the concept "family and moral values" was clarified on the basis of the analysis of scientific psychological and pedagogical literature. Experimental work was carried out among students of 1,2,3 courses of the specialty "Pedagogy and Psychology" of the Kazakh National Pedagogical University named after Abay, within the framework of which they tried to determine whether the family value is significant in the student environment.
\end{abstract}

Justification of the novelty of the work. The authors attempted to reveal for the first time among students of a pedagogical university their real relation to the family, to family and moral values.

Keywords: Expriment, values, family and moral values, formation, students, attitude to the family.

\section{INTRODUCTION}

The process of forming values of the family was not in the first place among student youth. Much more important for them is material well-being, higher education, communication with friends.

The purpose of the research was to reveal the main characteristics of family and moral values of youth and to describe some of the results of psychological and pedagogical diagnostics, as well as to construct methodological recommendations on the formation of family and moral values among students.

The analysis of the basic concepts of research based on the study of philosophical, psychological, pedagogical, cultural, sociological, literature, government documents and analytical materials of the

Address correspondence to this article at the Kazakh State National University of al-Farabi, Almaty, Kazakhstan; Tel: +77073851878;

E-mail: zhanat2006@mail.ru
Ministry of Education and Science of the Republic of Kazakhstan, generalization, and interpretation of scientific data, experiment.

The urgency of the problem of the formation of family values in modern youth is also conditioned by the lack of motivation for spiritual and moral development and improvement of the younger generation; ignorance of students of spiritual and moral family values; spread of modern forms of cohabitation, unconscious parenting, abortion, unwillingness to have children among young people;

Analysis of special literature and dissertational studies of Kazakhstani scientists showed that the education of family and moral values among students as an independent topic has not been considered so far.

The urgency and insufficient elaboration of the problem in the Kazakh science determined the choice of the research topic. 
The purpose of this study consisted in revealing the main characteristics of family and moral values of youth and describing some of the results of psychological and pedagogical diagnostics.

For the first time, the questions of changing roles in the family were examined in detail by American sociologists G. Parsons and W. Good [1]. Considering the modern nuclear family as the result of the evolution of society from an agrarian to an industrial one, American researchers drew attention to two trends in its development. On the one hand, the family exists relatively autonomously from other social structures and institutions, and on the other, its dependence on the social and professional structure of society [2].

In some social classes and strata of society, a new type of family begins to be created, successfully combining the value orientation of the couple to create their own family and their professional interests related to a focus on "achieved status", ie to a career in a chosen profession. This type was called "bicarrier family" [3].

Analyzing the philosophy of Nietzsche, Heidegger notes that the value of the essence lies in the fact that value point implies that seizes looking eye. Value is at the point of the eye, the point of the eye for such a look, which something fetishes or how we say something calculates, but it must be treated differently. Value is value, as long as it is recognized and meaningful. The point of the eye sets eyesight on something which should follow [4].

It should be noted that the family, according to scientists, is one of the greatest values created by mankind in the history of its existence.

Socio-psychological aspects of the study of values have become the subject of research by such scientists as G.A. Ball, A.A. Bodalev [5].

By most scientists, the concept of "value" is characterized as the identification of characteristics characteristic of all forms of social consciousness; significance, normativity, utility, necessity, expediency. The concept of "value" embraces a wide range of material and spiritual phenomena that serve as a condition for its formation [6].

E.S. Markaryan identifies values as an important element of culture, while culture is understood as a process, the result of human activities. It contains universal values: Moral, spiritual, aesthetic, etc. They are in a concentrated form is manifested experience of the people, so it is cultural values determine the image and style of life, human behavior, the nature of perception of life, constitute the basis of a kind of human behavior [7].

Of great interest was the classification of $\mathrm{N}$. Hartmann's values. In his scientific work, he singled out classes of values, from the lower to the higher:

I. The values of the good, covering all the values useful to us and employees means ...

II. The values of pleasure, usually called "pleasant."

III. Life values, inherent in all living things ... Everything that is useful for life ...

IV. Moral values covered by the notion of "good".

V. Aesthetic values covered by the concept of "beautiful."

VI. Cognitive values; actually only one ... "truth" [8].

Hartmann believed that values are revealed in the process of human life. In this process, the value consciousness is modified, but the values themselves remain unchanged. It should be noted that the scientist denied the importance and significance of one value over another [9].

The great Kazakh poet, the founder of Kazakh written literature, Abai Kunanbayev, spoke about the problems and disadvantages of educating the younger generation in the family from the parents, or rather in the 10th word of edification, wrote: "From the very beginning of life you will deceive the child, promising him one thing or another. And you will be glad that you managed to deceive. Who will you blame when he grows up to be a liar? Teach him foul language, abuse others, just defending him: "Do not touch this stubborn," you indulge his mischief. Is this your upbringing? And are you expecting mercy from this child? "[10].

When considering the family-moral values of A.M. Korshunov argues that for the individual value is what serves his interests, which contributes to his physical and spiritual development. We believe that he is right, paying attention to the fact that not every value is a value. Value, in his opinion, represents the positive significance or function of certain phenomena in the systems of sociohistorical activity of man. Phenomena 
that play a negative role in social development can be interpreted as negative values. The value is all that is included in social progress, serves him [11].

\section{METHODS}

The methodological basis was the researches have made an axiological, revealing the essence of value orientations and their importance for the education of students of the pedagogical high school, the personoriented, recognizing the personal development of subjects in the educational process of the university as a system-forming factor.

\section{RESULTS}

The conducted research has shown that the structure of value preferences of modern youth can be divided into three subgroups:

1) The first group of values: work, communication with peers, leisure;

2) The second group of values: health, education, family, marriage, love;

3) The third group of values: religion, society, country, habitat.

The processed results were given by the following indicators:

1) the overwhelming majority of girls believe that the highest priority for the near future is: to obtain a higher education is $65.5 \%$, and for the guys, the priority was material prosperity is $34 \%$.

2) In the second place, the material well-being of girls is $19 \%$.

3) The family takes the third place both in girls $(14.3 \%)$ and in boys is $23 \%$.

4) Communication with friends takes the fourth place as for girls is $1.2 \%$ and for boys is $14 \%$.

5) The registered marriage is preferred by the overwhelming majority of respondents $62 \%$. Less than half of the surveyed guys $46 \%$ chose a "registered" marriage.

6) $79 \%$ of respondents said that the priority for marriage is love, just the absolute majority of respondents answered; $9 \%$ of the girls noted the financial situation; $7 \%$ social status and $5 \%$ chose the category "other", where the answers "all the above listed" and "mind" were most often met.

Making informed decisions on the issues of formation of family and moral values cannot be carried out without engaging in a comprehensive analysis and assessment of the experience of the world's educational systems, taking into account their weighted interpretation, critical processing and appropriate adaptation to public life and the formation of family and spiritual and moral values among young people.

It should be noted that relations in the family can be used to judge the family values of other marital and family spheres. Intermittent, conflictual relations are accompanied not by established or not reached by spouses of value, and on the contrary: equal and flexible, creative relations are inherent in those married couples who in their activities embodied the desired values. Through the relationship begins to form a system of values of the family, in the same way, values form the entire structure of relations.

Family values are due to the uniqueness and social importance of the family. Relationships between spouses, children, and parents over the past decades have rapidly changed, the emotional and psychological side of family-marriage relations has gained increasing value. Much attention is paid to ideological and ideological and moral directions in educational work.

Being a unit of society, the family reflects its ideological, political and moral foundations. Among the spiritual values of the family, ideological values occupy the most important place. Family values include documents, memories, letters, awards. Each of them is a testimony of the life and deeds of relatives and relatives. A careful attitude to relics is a source of moral strength, ideological conviction, spiritual continuity of generations.

Summarizing the above, we present the views of Kazakh thinkers about family and moral values in Table 1.

At the same time, it is difficult for a modern person living in a technology who has received the opportunity for comfortable being and pleasures to perceive the family as a value since The new way of life concentrates man on the priority of his own individualistic "I". All this affects the family way of life, significantly affects the sphere of family relations, leads to the loss of spiritual and moral family values. 
Table 1: Views of Kazakh Thinkers about Family and Moral Values

\begin{tabular}{|c|c|c|}
\hline № & Kazakh thinkers & Pedagogical views \\
\hline \hline 1 & G. Balasagun (XIc.) & If you want to be respected, then be ready to respect others. \\
\hline 2 & MahmoudKashkari (XIc.) & All difficulties will pass, be patient, wait for the arrival of happiness. \\
\hline 3 & Leather Ahmet Yassaui (XIlc.) & Treat everyone with friendliness, sacrifice your pure soul for them. \\
\hline 4 & Saif Sarai (XIV century) & If you want to be respected, then be merciful \\
\hline 5 & Shalkiyyz zhyrau (XIV c.) & Do not humiliate others, and do not expect help from them if you humiliate. \\
\hline
\end{tabular}

The problem of educating family and moral values among students in pedagogical studies is "broken down" into a number of particular problems in the development of family and moral values of students' culture, in the education of certain qualities, skills, skills, characteristics.

Summarizing the above, we define values as internal criteria of morality, spirituality, family, by which he is guided in his behavior in order to follow the norms of society.

By family and moral values we mean a holistic inner core that recognizes the experience of cultural-national, higher spiritual and moral bases for the benefit of one's own "I", another society.

\section{THE DISCUSSION}

Our experimental work passed among students of 1,2,3 courses of the specialty "Pedagogy and Psychology" of the Kazakh National Pedagogical University named after Abay. The sample was about 80 people.

In the course of the work, in order to fulfil the purpose of the study the following tasks were singled out:

to clarify the place among the other values among students in the family, -to understand the meaning of young people in the concept of "family";

- explore what values of family life (traditions, children, love, support) are most important for young people.

In order to carry out the experimental work, we selected: M. Rokeach's value questionnaire; method of analyzing the attitude of young people to the family and its values.

M. Rokich proposed a theoretical model for the study of human value orientations (within the framework of the cognitive approach) and presented an effective tool for measuring them. As the main diagnostic construct, the author of the test considers the direction of the individual, understood as the significance for a person of certain life goals and value orientations, with which he is guided in his life.

Further, we tried to present the results of students' values orientation:

The attitude of young people towards early marriage was positive, but since students value education in society, they preferred to get a higher education in the beginning.

According to the results of the questionnaire, the head should be a man, but other results were obtained on this question, as well as answers to the question who should bring income.

On the question: did young people want to marry in general or were important for the career and job promotion with higher education, with the coordination of their actions and authority, the majority of respondents answered positively, having determined marriage to be a priority.

As the age at which to marry young people identified: $87 \%-20-30$ years old, $10 \%-18-20$ years old, $3 \%$ of 30 and older.

Summarizing the analysis of the importance of family values in the structure of parents' educational resources, a number of conclusions can be drawn.

First, the value system of the family has a powerful potential of educational influence on the younger generation in terms of its personal development.

Secondly, the distinctive system of values of the new era has not yet been formed. This is the main difficulty in the implementation of the educational process in a changing society: there are no sustainable guidelines for future development, a long-term strategy of social priorities is not defined. 
From the results obtained, it follows that the formation of family values is not the first priority for student youth. Much more important for them is material well-being, higher education, communication with friends. The prestige of higher education is sufficiently increased as the higher school realizes the needs of the society, prepares the necessary specialists, and today the number of students who are confident that after graduation they will manage to have a decent material reward in the chosen profession.

\section{CONCLUSION}

The study has been the result of a number of reasons that caused the urgency of educating family and moral values problem discussion.

This study allowed us to draw the following conclusions. The essence of the concept of "value" was substantiated, the content of the concept "family and moral values" was clarified on the basis of the analysis of scientific psychological and pedagogical literature.

We conducted an experimental work among students of 1,2,3 courses of the specialty "Pedagogy and Psychology" of the Kazakh National Pedagogical University named after Abay, within the framework of which they tried to determine whether the family value is significant in the student environment.
Based on the results of the ascertaining experiment, methodological recommendations on the formation of family and moral values were compiled. Among the students, familiarization debates were held on the topic "Family and moral values and their role in our life".

\section{REFERENCES}

[1] Parsons T, Bales R. Family, Socialization and Interaction Process. - London, 2006; p. 422.

[2] Good W. World Revolution and Family Patterns. - New York., 2003.

[3] Rapoport RN, Rapoport RR. Dual career family: reexamined. - L., 1976.

[4] Heidegger M. Nietzsche: in 2 t. St. Petersburg: Vladimir Dal, 2006; p. 603

[5] Ball GA, Medintsev VA. The set-theoretic method of describing processes and its application in psychology: a monograph. - K .: Pedagogical Dumka, 2016.

[6] Bodalev AA. Personality, and Communication. - Moscow: International Pedagogical Academy, 2005; p. 328.

[7] Rokeach M. The nature of human values. N.Y.: Free Press, 2003.

[8] Margaryan ES. Humanism of the XXI century. The ideology of self-preservation of mankind. - Yerevan: RAU Publishing House, 2008.

[9] Hartmann N. Zur Grundlegung der Ontologie. - Berlin: De Gruyter, 2005.

[10] Abay book of upbringing. Poems. Word of the tenth. A. 2003; p. 160

[11] Korshunov AM. Social cognition, value, and evaluation. Philosophy. Nauka.-M., 2007; № 6.

Received on 15-08-2018

Accepted on 17-09-2018

Published on 03-10-2018

\section{DOI: https://doi.org/10.6000/2292-2598.2018.06.03.3}

(C) 2018 Absatova et al.; Licensee Lifescience Global.

This is an open access article licensed under the terms of the Creative Commons Attribution Non-Commercial License (http://creativecommons.org/licenses/by-nc/3.0/) which permits unrestricted, non-commercial use, distribution and reproduction in any medium, provided the work is properly cited. 